\title{
Effects of BDNF polymorphism and physical activity on episodic memory in the elderly: a cross sectional study
}

Anne Canivet ${ }^{1 *}$, Cédric T. Albinet ${ }^{1,2}$, Nathalie André $^{1}$, Jean Pylouster ${ }^{1}$, Montserrat Rodríguez-Ballesteros $^{3}$, Alain Kitzis $^{3}$ and Michel Audiffren ${ }^{1,4}$

\begin{abstract}
Background: The brain-derived neurotrophic factor (BDNF) concentration is highest in the hippocampus compared with that in other brain structures and affects episodic memory, a cognitive function that is impaired in older adults. According to the neurotrophic hypothesis, BDNF released during physical activity enhances brain plasticity and consequently brain health. However, even if the physical activity level is involved in the secretion of neurotrophin, this protein is also under the control of a specific gene. The aim of the present study was to examine the effect of the interaction between physical activity and BDNF Val66Met (rs6265), a genetic polymorphism, on episodic memory.

Methods: Two hundred and five volunteers aged 55 and older with a Mini Mental State Examination score $\geq 24$ participated in this study. Four groups of participants were established according to their physical activity level and polymorphism BDNF profile (Active Val homozygous, Inactive Val homozygous, Active Met carriers, Inactive Met carriers). Episodic memory was evaluated based on the delayed recall of the Logical Memory test of the MEM III battery.

Results: As expected, the physical activity level interacted with BDNF polymorphism to affect episodic memory performance $(p<.05)$. The active Val homozygous participants significantly outperformed the active Met carriers and inactive Val homozygous participants.

Conclusion: This study clearly demonstrates an interaction between physical activity and BDNF Val66Met polymorphism that affects episodic memory in the elderly and confirms that physical activity contributes to the neurotrophic mechanism implicated in cognitive health. The interaction shows that only participants with Val/Nal polymorphism benefited from physical activity.
\end{abstract}

Keywords: Physical activity, Aging, BDNF Val66Met polymorphism, Episodic memory, Cognition

\section{Background}

Old age is often accompanied by functional and structural changes in the central nervous system. In normal aging, the decrease in the hippocampal volume is generally associated with episodic memory declines [1]. However, the cognitive performances of older adults significantly differ [2]. As age increases, brain resources decrease, and the influence of genetics on cognition becomes increasingly apparent. Genetic variations can explain differences in an individual's general cognitive ability [3, 4], and the heritability of cognition increases with age [5], from

\footnotetext{
* Correspondence: anne.canivet@univ-poitiers.fr

'Université de Poitiers, Centre de Recherches sur la Cognition et

l'Apprentissage, CNRS UMR 7295, Poitiers, France

Full list of author information is available at the end of the article
}

approximately $30 \%$ in childhood to as much as $80 \%$ in adulthood [6].

In humans, a single nucleotide polymorphism (SNP) of the brain-derived neurotrophic factor (BDNF) gene, named BDNF Val66Met gene polymorphism or rs6265 SNP, causes a valine (Val) to methionine (Met) substitution at codon 66, which reduces the secretion and distribution of BDNF in the brain [7] to affect episodic memory functioning [8-10] and reduce hippocampal volume [10-12]. The Met allele exerts its effect by impacting intracellular trafficking and the activity-dependent secretion of BDNF. It is associated with reduced neurogenesis and weak cognitive performances. However, other studies have shown that the relationship between the Met allele and cognitive 
performances is not clearly established [13-15]. A metaanalysis has demonstrated that SNP rs6265 is not associated with hippocampal volume in healthy individuals [16]. Moreover, Erickson et al. [17] showed that Val/Val carriers aged 65 outperformed Met carriers of the same age on an executive functioning task, whereas contradictory results were observed at an average age of 75 . Similarly, recent evidence suggests that the functions of the fronto-striatal circuits are more efficient in elderly BDNF Met-allele carriers than in individuals who are homozygous for Val [17-21]. Cognitive processes assessed using event-related potentials (ERPs) seem to vary according to the isoform of the gene $[21,22]$. Taken together, these results suggest that the $B D N F$ Val66Met polymorphism differently affects various cognitive processes. Currently, the beneficial effect of Val/ Val homozygosity on brain structure and brain functioning compared with Met carriers is controversial.

BDNF - a member of the nerve growth factor family plays an important role in neurogenesis and is implicated in several molecular processes in the central nervous system [23]. In the brain, the expression level of BDNF is highest in the hippocampus, a key region of neural plasticity and adult neurogenesis [24, 25], and this factor is well-known to play an important role in learning and long-term memory [26].

Studies have demonstrated that regular physical activity (PA) is associated with gray matter volume increases in the hippocampus [27] and better memory performance [28]. Study showed that PA increases hippocampal volume, which is implicated in episodic memory [29]. According to these authors, the relationship between exercise and brain health could be explained by the neurotrophic hypothesis, which involves the release of BDNF during exercise [30-32].

In fact, animal studies have shown that the level of BDNF increases in response to exercise [33, 34], and a high level of BDNF subsequently promotes neurogenesis, synapse plasticity, neuronal cell survival and arborization $[23,35]$. In humans, the level of BDNF was found to increase after acute exercise [36, 37] or after a 16-week multimodal exercise program in older adults [38]. Thus, an increased concentration of serum BDNF is considered one of the primary molecular pathways by which exercise may improve cognition. PA is shown to increase hippocampal volume and improve episodic memory performance and affects the BDNF level, whereas BDNF Val66Met impacts BDNF availability, neuronal survival and morphology and alters neuronal functioning [7, 39]. Therefore, we herein investigated the effect of the interaction between BDNF Val66Met polymorphism and PA on episodic memory performance because both these factors are related to BDNF production.

Only four studies highlighted an interaction between BDNF Val66Met polymorphism and PA on cognitive performance in older adults, and the results were mixed. A first study of community elders aged 65 years and older showed that the cognitive performances of inactive participants are associated with a decrease in the general cognitive performance as a function of the number of Met alleles in the polymorphism [40]. In a second study of participants aged 60 years and older with mild cognitive impairment, only the BDNF-Met genotype group subjected to a PA program showed a significant increase in the peripheral BDNF level but no differences in general cognition [41]. A third study, in which the participants were 30 to 54 years of age, showed that a high level of PA compensated for the weak performances in working memory of Met carriers but did not significantly affect the Val homozygous individuals [42]. Because these middle-aged participants exhibit less genetic heritability than older individuals [4], extrapolating these findings to older people is difficult. The fourth study showed that only Val homozygous participants benefited from PA, as evidenced by larger hippocampal grey matter and temporal lobe volumes, whereas higher levels of PA were associated with smaller temporal lobe volumes in Met carriers [43]. In these four studies, the BDNF genotype appears to modulate the effects of physical exercise on level of BDNF, cognition and/or brain volume, but the direction of the interaction remains unclear. Testing several alternative hypotheses would be appropriate in order to clarify the direction of this interaction, which was the purpose of the present study.

According to a first hypothesis, if the Met allele negatively affects intercellular trafficking and activity-dependent secretion and PA increases the hippocampal BDNF level, the episodic memory of Met carriers should benefit more from PA than that of Val/Val homozygous individuals. In other words, active Met carriers should perform better in episodic memory tasks than inactive Met carriers, whereas PA should not affect individuals who are homozygous for Val. According to a second hypothesis and in line with Brown's work [43], PA should optimize the different molecular pathways implicated in cognition and magnify the effect of the Val allele. In other words, only the BDNF-Val homozygous individuals should benefit from the positive effects of PA on episodic memory. The main objective of this study was to validate one of these two hypotheses.

\section{Methods \\ Study}

Data were collected from the "PRAUSE" survey conducted in Poitou-Charentes, France, from 2011 to 2013. Four hundred and sixty-six retired volunteers aged 55 years and older (mean age $=75.72$; $\mathrm{SD}=9.84$ ) were included in the survey. Nonnative French speakers were excluded from participation. The survey was administered at home and in three sessions, with durations of 
1.5 to $2 \mathrm{~h}$ each. A battery of cognitive tests and questionnaires were administered during these three sessions, and buccal swabs were taken during session 1 . The 466 subjects did not all participate in the three sessions.

\section{Participants}

Only 205 participants (mean age $=72.72$; $\mathrm{SD}=9.16$ ) of the 466 volunteers included in the study completed all tests and questionnaires required to verify the hypotheses mentioned in the introduction (see Fig. 1).

All participants provided written informed consent to participate to this survey, which was approved by two national ethics comities: (1) the survey received the "general interest and statistical quality" label from the "Conseil National de l'Information Statistique" (CNIS) [French National Council of Statistical Information] (Visa n²012X907RG); (2) the survey also received authorization $\mathrm{n}^{\circ} 1593815$ from the "Commission Nationale de l'Informatique et des Libertés” (CNIL) [French
National Commission on Informatics and Liberty] (deliberation $\mathrm{n}^{\circ} 2012-375$ ).

\section{Cognitive assessments}

Mini mental state examination

General cognition was evaluated based on the Mini Mental State Examination during the first session, and cognitive impairment (exclusion criterion) was defined as a score below 24 [44].

\section{Logical memory test II}

The Delayed Score of the Logical Memory II subtest of the Wechsler Memory Scale, revised version (WMS-III) $[45,46]$, was used to assess episodic memory performance. Only story B was read to the participants. Participants listened to the story twice. Immediately after each reading, they were asked to verbally recall as many items as possible about the story. The participants were asked to respond to other questionnaires for twenty minutes,

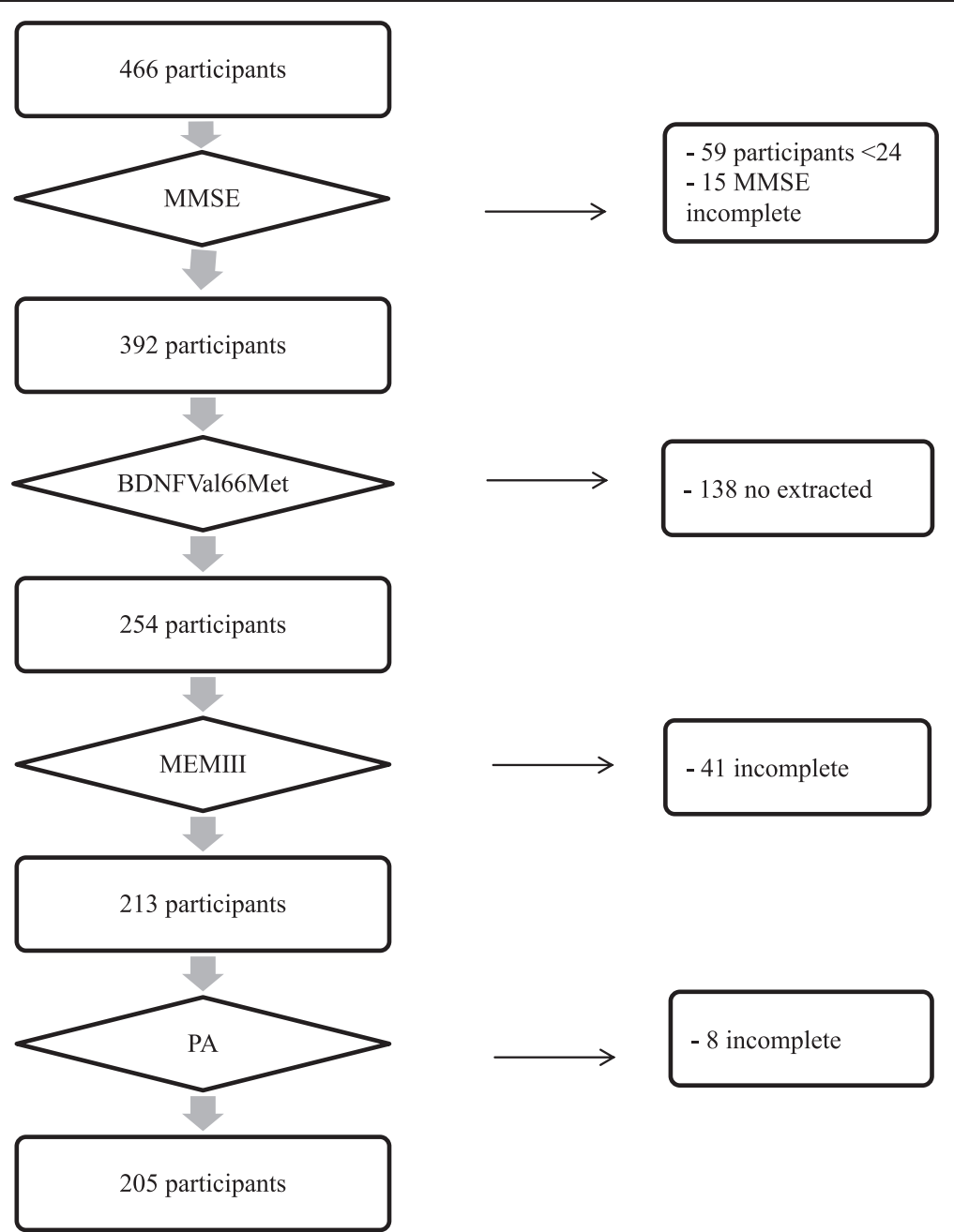

Fig. 1 Flow chart describing the selection process of participants. Note: MMSE = Mini Mental State Examination; BDNF Val66Met = Brain derived neurotrophic factor gene polymorphism; MEMIII = Logical Memory test of the MEM III battery; PA = Level of physical activity 
and they were then asked to recall all remembered items of the story without any additional listening. The performance in this task was defined as the total number of correctly recalled items about the story during the delayed recall test. This delayed recall score $(\max .=25)$ is considered an index of episodic memory. We used this test because it is a validated evaluation of episodic memory used worldwide, which offers standardized measures easily comparable with other studies.

\section{Genotyping}

DNA was extracted from buccal cells using the QIAamp DNA Blood Mini Kit (QIAGEN Group) according to the protocol supplied by the manufacturer. SNPs were genotyped using polymerase chain reaction and restriction fragment length polymorphism (PCR-RFLP) analysis. The BDNF polymorphism Val66Met (rs6265) was amplified by PCR using the forward primer $5^{\prime}$-GCCTACCCAGGT GTGCGG-3' and the reverse fluorescent primer 5'-FAMGAGGAGGCTCCAAAGGCAC-3'. The PCR products were digested with the restriction enzyme Hsp92II (Promega Corporation) and resolved by capillary electrophoresis in an ABI PRISM 3130 Genetic Analyzer (Life technologies).

Genetic data were analyzed using a dominance model such that Met carriers were combined into a single group because the Val/Met and Met/Met genotypes have been associated with decreased cognitive performance compared with Val-Val genotype [8-10].

\section{Physical activity}

\section{The NASA/JSC physical activity scale}

During the first session, all participants were asked to rate their regular weekly physical practice on a score from 0 to 7 with the NASA/JSC Physical Activity Scale [47] to identify their level of PA. We used these data to determine the participants' PA levels in case they left the study after the first session. This questionnaire determines the level of PA less accurately than the subsequent questionnaire that was completed in session 2 . It was used to include a maximum of participants and to solve the problem of missing data. The participants concerned by this classification method were considered active if their NASA/JSC physical activity score was strictly higher than 3. To increase the likelihood of observing a significant effect of PA on cognitive performance, we selected only the active participants with a body mass index less than 35 (10 participants); being overweight is generally related to impaired cognitive function [48]. Participants were classified as inactive if their NASA/ JSC physical activity score was strictly lower than 3 (127 participants were in this category). Thirty-nine participants scored at level 3 were considered not classifiable because knowing if they practice above or below the recommendations of the World Health Organization (WHO), described hereafter, was impossible.

\section{The Historical Leisure Activity Questionnaire (HLAQ)}

During the second session, the level of current PA was evaluated with the Historical Leisure Activity Questionnaire (HLAQ) [49]. This validated questionnaire was used to assess the history of PA weighted by their relative intensity. Participants were asked to report the frequency, type, intensity, and hours of PA performed during the present year. Using the Compendium of Physical Activities Tracking Guide 2011 [50], we obtained a specific metabolic equivalent (MET) for each PA. According to the HLAQ data and the compendium, we calculated the average energy expenditure (Mets-h/week) for each participant. According to WHO recommendations, we classified the participants above 7.5 METs-h/week in the active group and those below 7.5 METs-h/week in the inactive group.

\section{Groups constitution}

We established 4 groups of participants according to their level of PA (above and below 7.5 METs-h/week, from WHO recommendations) and polymorphism BDNF profile (Met Carriers vs. Val Homozygous) (see Table 1).

\section{The geriatric depression scale (GDS)}

The geriatric depression scale (GDS) was used to assess the depression level of participants [51, 52] because several studies showed an interaction between BDNF polymorphism and PA that affected the depression level [53, 54].

\section{The education level}

The education level was measured based on the number of years of formal education, from the first year of elementary school to the third year of a Ph.D. degree (1-20 years). The education level is well known to contribute to the cognitive reserve $[55,56]$ and strongly influences cognitive performance in older adults.

\section{The socioeconomic level}

The socioeconomic level was assessed from current monthly participants' income. The scale consisted of 12 classes of monthly income: less than $500 € /$ month; 500 $749 € /$ month; 750-999 €/month; 1000-1499 €/month; 1500-1999 €/month; 2000-2499 €/month; 2500-2999 $€ /$ month; 3000-3499 €/month; 3500-4499 €/month; 4500-5999 €/month; 6000-7499 €/month; more than 7500 $€ /$ month. In order to calculate the mean monthly income for each group, we took into account the highest value of the class selected by each individual. A maximal monthly income of $8000 €$ was assigned for the highest class. 
Table 1 Characteristics of the participants

\begin{tabular}{|c|c|c|c|c|c|c|}
\hline \multirow[b]{2}{*}{ GROUPS } & \multicolumn{2}{|l|}{ Active } & \multicolumn{2}{|l|}{ Inactive } & \multirow[t]{2}{*}{ Total or Average } & \multirow{2}{*}{$\begin{array}{l}\text { Effects of PA } \\
\text { and BDNF }\end{array}$} \\
\hline & Val/Nal & Met carriers & Val/Nal & Met carriers & & \\
\hline Participants (N) & 55 & 48 & 63 & 39 & 205 & \\
\hline Age (SD) & $69.69(7.70)$ & $70.07(7.70)$ & $77.27(9.42)$ & $72.93(9.55)$ & $72.72(9.16)$ & $\mathrm{PA}^{*}$ \\
\hline Gender (M/F) & $24 / 31$ & $31 / 17$ & $17 / 46$ & $16 / 23$ & $88 / 117$ & $\mathrm{PA}^{*}, \mathrm{BDNF}^{*}$ \\
\hline MMSE (SD) & $28.35(1.42)$ & $28.10(1.56)$ & $27.57(1.84)$ & $28.36(1.56)$ & $28.05(1.64)$ & NS \\
\hline Depression score (SD) & $6.83(5.15)$ & $5.85(4.96)$ & $9.61(5.37)$ & $8.71(5.97)$ & $7.81(5.51)$ & NS \\
\hline Education Level (SD) & $10.87(3.24)$ & $10.85(3.69)$ & $9.69(3.61)$ & $10.97(3.94)$ & $10.57(3.65)$ & NS \\
\hline Socioeconomic level (SD) & 2439.31 (941.49) & $2954.60(1644.08)$ & $1985.84(1214.15)$ & $2334.74(1065.70)$ & $2405.7(1283.9)$ & $\mathrm{PA}^{*}, \mathrm{BDNF}^{*}$ \\
\hline Hour/week of PA (SD) & $10.23(8.10)$ & $9.31(6.72)$ & $0.35(0.61)$ & $0.23(0.49)$ & $5.68(7.32)$ & $P A^{*}$ \\
\hline Mets-h/week of PA (SD) & $52.88(45.09)$ & $50(48.35)$ & $1.39(2.32)$ & $0.83(1.73)$ & 29.66 (42.93) & $P A^{*}$ \\
\hline
\end{tabular}

$P A^{*}$ significant main effect of $\mathrm{PA}, B D N F^{*}$ significant main effect of BDNF polymorphism, NS no effect of PA and BDNF

\section{Statistical analysis}

To examine the interaction between BDNF polymorphism and PA that affects episodic memory performance, we first tested the normality of our data distribution using the Lilliefors test. Episodic memory performances were normally distributed $(p<.01)$. Thus, we conducted an analysis of variance (ANOVA) on the delayed score of the logical memory test with PA level (active vs. inactive) and BDNF polymorphism (Met carriers vs. Val homozygous) as between-subjects factors. For significant results, mean comparisons were performed using Bonferroni corrections for multiple comparisons. We then conducted an analysis of covariance (ANCOVA) with age, gender and socioeconomic level as covariates. These three variables have been added as covariates because they are significantly associated to PA and BDNF polymorphism in our sample of participants (see Table 1). The two groups of inactive participants were significantly older and socioeconomically weaker than the two groups of active participants. The number of inactive men was significantly lower than the number of inactive women and the number of Met carrier women was significantly lower than the number of Val homozygous women. The Met carriers had a higher socioeconomic level than Val homozygous.

\section{Results}

Our population was divided into 3 allele frequency groups: 10 Met homozygous carriers, $77 \mathrm{Val} /$ Met carriers and 118 Val homozygous carriers, close to the Caucasian breakdown [7]. The allelic frequency was estimated based on the Hardy Weinberg Equilibrium using the $\mathrm{khi}^{2}$ test. The distribution of genotypes in the sample did not differ from the HardyWeinberg Equilibrium $(p=0.57)$. The ANOVA showed that PA or BDNF polymorphism did not affect episodic memory performance, whereas a significant interaction between PA and BDNF polymorphism did significantly affect episodic memory performance: $F(1,201)=7.06, p=.01, \eta \mathrm{p}^{2}=0.034$ (see Fig. 2). Post-hoc analyses (Bonferroni test) showed that the Inactive and Active Val homozygous carriers significantly differed $(p<.01)$, whereas the difference between Inactive and Active Met carriers did not reach significance. The results of the ANCOVA revealed that the BDNF polymorphism $\times$ PA interaction remained significant for the episodic memory performance: $F(1,198)=$ $6.05, p=.015, \eta^{2}=0.03$. Post-hoc analyses also confirmed the significant difference between Inactive and Active Val homozygous carriers $(p<.01)$.

\section{Discussion}

The present study examined the effect of the interaction between PA and BDNF Val66Met polymorphism on episodic memory in the elderly. The identification of the genetic background that influences one's cognition abilities is a challenging task. Physical exercise can mediate the increase of brain BDNF concentrations as an illustration of the gene-environment relationship. Thus, this research aimed to explain the combined influence of genetic polymorphism and one environmental factor (PA). Two opposite hypotheses that considered this interaction were formulated. According to the first hypothesis, PA might boost episodic memory performance in Met carriers because PA increases the level of hippocampal BDNF, which is thought to be deficient in this population, whereas PA should not affect BDNF-Val homozygous carriers. According to the second hypothesis, PA should magnify the effect of the Val allele, resulting in positive effect of PA on episodic memory performance for BDNF-Val homozygous participants only. As expected, we observed a significant interaction between $\mathrm{PA}$ and BDNF polymorphism on the delayed score of the logical memory test. First, this interaction shows that BDNF polymorphism modulates the relationship between PA and episodic memory performance, strongly suggesting that PA 


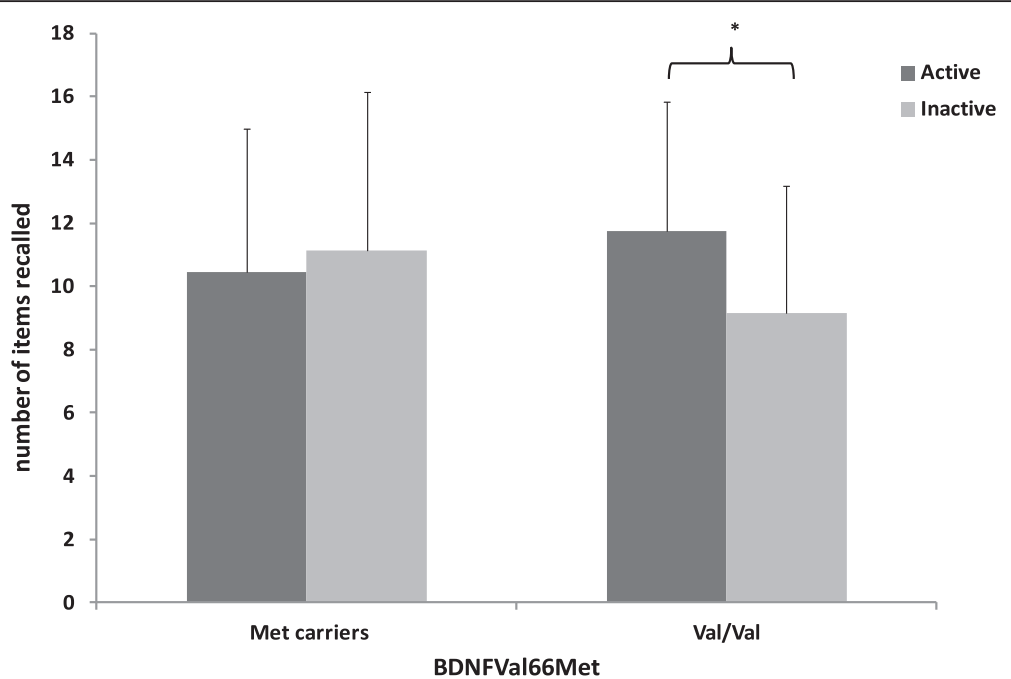

Fig. 2 Interaction between BDNF Polymorphism (Met carriers vs. Val/Nal) and Physical Activity (active vs inactive) on Episodic Memory Performance. Errors bars represent standard deviation. ${ }^{*} p<.01$

and BDNF share a common mechanism that influences episodic memory in older adults. More precisely, the direction of this interaction shows that regular PA is associated with better episodic memory only for Val homozygous participants. This result converges with the findings of Brown et al. [43], who showed that only active, Val-homozygous participants benefited from PA and exhibited a larger hippocampal grey matter volume. Clearly, the results of the present study favor the second hypothesis. Specifically, exercise-induced BDNF secretion is more efficient in Val homozygous than in Met carriers.

Since the publication of Egan et al. [7], the investigation of genetic associations between BDNF and cognition has produced mixed results, and these discrepancies can be attributed to the ethnic group, age of the participants or choice of controlled variables. Among the controlled variables influencing cognition, life habits, such as PA or the mental health and education level of the participants, are rarely controlled, but these factors are known to influence the cognitive performance of older people. The strength of the present study is that it highlighted the interaction between polymorphism and PA, a life habit recognized to benefit brain health. We showed that PA interacts with the BDNF Val66Met to affect the episodic memory performance. Thus, controlling the PA level is important when examining the putative impact of BDNF Val66Met on cognition in the elderly.

From a phylogenetic perspective, examining the link between the BDNF gene and PA would be interesting. According to a phylogenetic hypothesis [57], the necessity to be physically active is probably programmed into our genes and has remained relatively stable for the past
10000 years [58]. We know that our Homo sapiens ancestors had to be highly active for their survival and that the Val homozygote BDNF, which is the wild-type genotype, secretes proteins more effectively. The advantage of the Val homozygous genotype for brain BNDF secretion, hippocampal volume and episodic memory performance could be magnified in active humans. The physical ability to find food and to use it as a source of energy for the brain could act in a cooperative association with mechanisms underlying cognitive functions [59] and increase the adapted survival strategies. We can hypothesize that long ago, these two features, PA and $\mathrm{BDNF} \mathrm{Val} / \mathrm{Val}$, linked in order to be efficient.

If the wild-type, $\mathrm{Val} / \mathrm{Val}$, seems to optimize the effects of BDNF secretion for people practicing regular PA, the subsistence of the Met allele (homozygous and heterozygous) in the population must be linked to both the evolution of the species and its life habits. Our results may also be interpreted in light of the possibility that sedentary lifestyle is a phylogenetically new phenomenon, with negative consequences on health, brain and behavior, whereas the human genome, a product of a very long evolutionary process, was built for active organisms fighting for their survival. In other words, the different genetic variations of some genes, like BDNF Val66Met, remain in the population because the survival of sedentary people is being facilitated by the development of human technology.

Moreover, some studies have demonstrated that Met allele carriers are more protected during aging than the Val/Val group, especially with respect to cognitive functions that involve the prefrontal cortex (PFC), such as executive functions $[19,20,60]$. Specifically, Erickson 
et al. [42] showed that this advantage was magnified by PA for Met carriers. These results appear to contradict our results and other results obtained in several studies assessing the relationship between cognition and BDNF Val66Met [14, 15]. However, Getzmann et al. [22] consider that the effect of BDNF polymorphism may differ depending on the brain areas supporting the different cognitive functions. Future studies should more precisely examine the cognitive functions that are negatively affected by specific iso-forms of the BDNF Val66Met polymorphism using more selective cognitive evaluations; i.e., a large battery of two or three cognitive tests per cognitive function that declines with age, mainly the speed of information processing, episodic memory and executive functions. Currently, PA has been shown to enhance cognitive vitality and facilitate cognitive tasks that rely on the hippocampus and the prefrontal cortex. Thus, future research should explore whether the effect of PA on various domains of cognitive performance depends on the BDNF Val66Met polymorphism.

Moreover, these findings could be attributed to an alternative explanation. According to Egan et al. [7], Pezawas et al. [61] and Hariri et al. [62], Met carriers are subject to a stronger diminution of resources with age than Val homozygous individuals. Even if they practice PA, which increases the level of BDNF [37], reaching the threshold of protein that counterbalances the effects of aging is more difficult for BDNF Met carriers. Consequently, the episodic memory performances of Met carriers do not change, irrespective of PA. By contrast, PA may help Val homozygous individuals to attain the optimal threshold of BDNF concentration and outperform their inactive Val homozygous counterparts.

Four main limitations can be noted. First, this study was cross-sectional, and the measure of physical activity was based on the participants' self-reports. Therefore, reporting may have been subject of bias due to the subjective perception of participants about their PA level. However, the HLAQ questionnaire and the NASA/JSC Physical Activity Scale are widely recognized and wellvalidated instruments. Second, this cross-sectional study design limits the ability to interpret these results as a causal relationship between physical activity and cognition; conversely, better cognitive functioning may result in individuals being more physically active. Third, the brain BDNF levels were not assessed through lumbar puncture because this methodology was not compatible with the PRAUSE protocol, and therefore the interaction between PA and BDNF polymorphism is only associative. Fourth, a haplogroup (group of genes transmitted together) may exert protective or compensative effects on certain alterations in the secretion of proteins linked to the polymorphism genes. For example, several studies have demonstrated that for the Met allele, the Asian- type population [63] seems to be protected from cognitive aging. This ethnic influence was not considered in our study, which was conducted in France on a mostly Caucasian population. Future studies should adopt a randomized controlled trial approach to determine in a causal link for the benefit of PA training programs to BDNF Val homozygous carriers and various types of population in order to generalize the results.

\section{Conclusions}

To conclude, we observed a significant interaction between PA and BDNF polymorphism that affected the delayed score of the logical memory test. This result shows that the association between PA and episodic memory was mediated by BDNF polymorphism because PA increased the episodic memory performance only in Val-Val homozygous participants.

\section{Abbreviations \\ BDNF: Brain-derived neurotrophic factor; HLAQ: Historical Leisure Activity Questionnaire; MEMIII: Logical Memory test of the MEM III battery; MMSE: Mini Mental State Examination; PA: Physical activity; SNP: Single nucleotide polymorphism; WHO: World Health Organization.}

\section{Competing interests}

The authors declare no potential conflict of interest with respect to the authorship and/or publication of this article.

\section{Authors' contributions}

MA, CA and NA conceived the idea of this study. MA, CA, NA and AK participated in the conception and design of the study. AC and JP carried out data collection. MRB extracted genotypes. AC conducted the statistical analyses. AC, CA, MA and MRB wrote the manuscript. AC, CA and MA, were involved in drafting or revising the manuscript critically for its content. All authors read and approved the final manuscript.

\section{Acknowledgments}

The PRAUSE survey was supported by the French National Research Agency (ANR-12-MALZ-005-01), the Regional Council of Poitou-Charentes, the European Funds for Regional Development (FEDER), the Poitou-Charentes Health Regional Agency, the Poitou-Charentes Regional Department for Youth, Sports and Social Cohesion, and Calyxis. The authors thank all study participants for their patience and the pollsters for data collection. The authors wish to thank the National Institute of Statistics and Economical Studies (INSEE) for their help in determining a representative sample of participants.

\section{Author details}

${ }^{1}$ Université de Poitiers, Centre de Recherches sur la Cognition et I'Apprentissage, CNRS UMR 7295, Poitiers, France. ${ }^{2}$ Institut National Universitaire Champollion, Place Verdun, 81000 Albi, France. ${ }^{3}$ Université de Poitiers, CHU de Poitiers, Laboratoire CiMoTheMA - EA 3808 Groupe « Génétique des maladies rares », Poitiers, France. ${ }^{4}$ Université de Poitiers, Maison des Sciences de l'Homme et de la Société, CNRS USR 3565, Poitiers, France.

Received: 31 October 2015 Accepted: 21 December 2015

Published online: 29 December 2015

\section{References}

1. Charlton RA, Barrick TR, Markus HS, Morris RG. The relationship between episodic long-term memory and white matter integrity in normal aging. Neuropsychologia. 2010;48:114-22.

2. de Frias CM, Loevden M, Lindenberger U, Nilsson L-G. Revisiting the dedifferentiation hypothesis with longitudinal multi-cohort data. Intelligence. 2007;35:381-92. 
3. Deary IJ, Spinath FM, Bates TC. Genetics of intelligence. Eur J Hum Genet. 2006;14:690-700.

4. Deary IJ, Yang J, Davies G, Harris SE, Tenesa A, Liewald D, et al. Genetic contributions to stability and change in intelligence from childhood to old age. Nature. 2012;482:212-5.

5. Deary I, Johnson W, Houlihan LM. Genetic foundations of human intelligence. Hum Genet. 2009;126:215-32.

6. Edmonds CJ, Isaacs EB, Visscher PM, Rogers M, Lanigan J, Singhal A, et al. Inspection time and cognitive abilities in twins aged 7 to 17 years: Age-related changes, heritability and genetic covariance. Intelligence. 2008;36:210-25.

7. Egan MF, Kojima M, Callicott JH, Goldberg TE, Kolachana BS, Bertolino A. The BDNF val66met polymorphism affects activity-dependent secretion of BDNF and human memory and hippocampal function. Cell. 2003;1 12:257-69.

8. Raz N, Rodrigue KM, Kennedy KM, Land S. Genetic and vascular modifiers of age-sensitive cognitive skills: effects of COMT, BDNF, ApoE, and hypertension. Neuropsychology. 2009;23:105-16.

9. Lim YY, Villemagne VL, Laws SM, Ames D, Pietrzak RH, Ellis KA, et al. Effect of BDNF Val66Met on memory decline and hippocampal atrophy in prodromal alzheimer's disease: a preliminary study. Plos One. 2014;9.

10. Miyajima F, Ollier W, Mayes A, Jackson A, Thacker N, Rabbitt P, et al. Brainderived neurotrophic factor polymorphism Val66Met influences cognitive abilities in the elderly. Genes Brain Behav. 2008;7:411-7.

11. Szeszko PR, Lipsky R, Mentschel C, Robinson D, Gunduz-Bruce H, Sevy S, et al. Brain-derived neurotrophic factor val66met polymorphism and volume of the hippocampal formation. Mol Psychiatry. 2005;10:631-6.

12. Bueller JA, Aftab M, Sen S, Gomez-Hassan D, Burmeister M, Zubieta J-K. BDNF Val66Met Allele is associated with reduced Hippocampal volume in healthy subjects. Biol Psychiatry. 2006;59:812-5.

13. Laukka EJ, Lovden M, Herlitz A, Karlsson S, Ferencz B, Pantzar A, et al. Genetic effects on old-age cognitive functioning: a population-based study. Psychol Aging. 2013;28:262-74.

14. Houlihan LM, Harris SE, Luciano M, Gow AJ, Starr JM, Visscher PM, et al. Replication study of candidate genes for cognitive abilities: the Lothian Birth Cohort 1936. Genes Brain Behav. 2009:8:238-47.

15. Harrisberger F, Spalek K, Smieskova R, Schmidt A, Coynel D, Milnik A, et al. The association of the BDNF Val66Met polymorphism and the hippocampal volumes in healthy humans: a joint meta-analysis of published and new data. Neurosci Biobehavior Rev. 2014:42:267-78.

16. Mandelman SD, Grigorenko EL. BDNF Val66Met and cognition: all, none, or some? A meta-analysis of the genetic association. Genes Brain Behav. 2012;11:127-36.

17. Erickson Kl, Kim JS, Suever BL, Voss MW, Francis BM, Kramer AF. Genetic contributions to age-related decline in executive function: a 10-year longitudinal study of COMT and BDNF polymorphisms. Front Hum Neurosci. 2008;2:11.

18. Foltynie T, Lewis SGJ, Goldberg TE, Blackwell AD, Kolachana BS, Weinberger $D R$, et al. The BDNF Val(66)Met polymorphism has a gender specific influence on planning ability in Parkinson's disease. J Neurol. 2005;252:833-8.

19. Gajewski PD, Hengstler JG, Golka K, Falkenstein M, Beste C. The Met-allele of the BDNF Val66Met polymorphism enhances task switching in elderly. Neurobiol Aging. 2011;32:2327. e2327-2327.e2319.

20. Gajewski PD, Hengstler JG, Golka K, Falkenstein M, Beste C. The Metgenotype of the BDNF Val66Met polymorphism is associated with reduced Stroop interference in elderly. Neuropsychologia. 2012;50:3554-63.

21. Harris SE, Fox H, Wright AF, Hayward C, Starr JM, Whalley LI, et al. The brain-derived neurotrophic factor Val66Met polymorphism is associated with age-related change in reasoning skills. Mol Psychiatry. 2006;11:505-13.

22. Getzmann S, Gajewski PD, Hengstler JG, Falkenstein M, Beste C. BDNF Val66Met polymorphism and goal-directed behavior in healthy elderly evidence from auditory distraction. Neuroimage. 2013;64:290-8.

23. Park H. Poo M-m: Neurotrophin regulation of neural circuit development and function. Nat Rev Neurosci. 2013;14:7-23.

24. Conner JM, Lauterborn JC, Yan Q, Gall CM, Varon S. Distribution of brain-derived neurotrophic factor (BDNF) protein and mRNA in the normal adult rat CNS: Evidence for anterograde axonal transport. J Neurosci. 1997:17:2295-313.

25. de Quervain DJF, Papassotiropoulos A. Identification of a genetic cluster influencing memory performance and hippocampal activity in humans. Proc Natl Acad Sci U S A. 2006;103:4270-4.

26. Cunha C, Brambilla R, Thomas KL. A simple role for BDNF in learning and memory? Front Mol Neurosci. 2010;3:1.
27. Erickson Kl, Leckie RL, Weinstein AM. Physical activity, fitness, and gray matter volume. Neurobiol Aging. 2014;35(Supplement 2):S20-8.

28. Bherer L, Erickson Kl, Liu-Ambrose T. A review of the effects of physical activity and exercise on cognitive and brain functions in older adults. J Aging Res. 2013;2013:657508.

29. Erickson KI, Voss MW, Prakash RS, Basak C, Szabo A, Chaddock L, et al. Exercise training increases size of hippocampus and improves memory. Proc Natl Acad Sci. 2011;108:3017-22.

30. Coelho FGM, Gobbi S, Andreatto CAA, Corazza DI, Pedroso RV, SantosGalduróz RF. Physical exercise modulates peripheral levels of brain-derived neurotrophic factor (BDNF): A systematic review of experimental studies in the elderly. Arch Gerontol Geriatr. 2013;56:10-5.

31. Ding Q, Vaynman S, Akhavan M, Ying Z, Gomez-Pinilla F. Insulin-like growth factor I interfaces with brain-derived neurotrophic factor-mediated synaptic plasticity to modulate aspects of exercise-induced cognitive function. Neuroscience. 2006;140:823-33.

32. Szuhany KL, Bugatti M, Otto MW. A meta-analytic review of the effects of exercise on brain-derived neurotrophic factor. J Psychiatr Res. 2015;60:56-64.

33. Neeper SA, Gomezpinilla F, Choi J, Cotman C. Exercice and brain neurotrophins. Nature. 1995;373:109.

34. Vaynman S, Ying Z, Gomez-Pinilla F. Hippocampal BDNF mediates the efficacy of exercise on synaptic plasticity and cognition. Eur Journal of Neurosci. 2004:20:2580-90.

35. Vaynman S, Ying Z, Gomez-Pinilla F. Exercise induces BDNF and synapsin I to specific hippocampal subfields. J Neurosci Res. 2004;76:356-62.

36. Huang $T$, Larsen $K T$, Ried-Larsen $M$, Moller NC, Andersen LB. The effects of physical activity and exercise on brain-derived neurotrophic factor in healthy humans: A review. Scand J Med Sci Sports. 2014;24:1-10.

37. Knaepen K, Goekint M, Heyman EM, Meeusen R. Neuroplasticity - ExerciseInduced Response of Peripheral Brain-Derived Neurotrophic Factor A Systematic Review of Experimental Studies in Human Subjects. Sports Med. 2010;40:765-801.

38. Vaughan $S$, Wallis M, Polit D, Steele M, Shum D, Morris N. The effects of multimodal exercise on cognitive and physical functioning and brain-derived neurotrophic factor in older women: a randomised controlled trial. Age Ageing. 2014:43:623-9.

39. Frielingsdorf H, Bath KG, Soliman F, DiFede J, Casey BJ, Lee FS. Variant brainderived neurotrophic factor Val66Met endophenotypes: implications for posttraumatic stress disorder. Psychiatric and neurologic aspects of war. Ann N Y Acad Sci. 2010;1208:150-7.

40. Kim J-M, Stewart R, Bae K-Y, Kim S-W, Yang S-J, Park K-H, et al. Role of BDNF val66met polymorphism on the association between physical activity and incident dementia. Neurobiol Aging. 2011;32.

41. Crispim Nascimento CM, Pereira JR, de Andrade LP, Garuffi M, Ayan C, Kerr DS, et al. Physical exercise improves peripheral BDNF levels and cognitive functions in mild cognitive impairment elderly with different BDNF Val66Met genotypes. J Alzheimers Dis. 2015;43:81-91.

42. Erickson Kl, Banducci SE, Weinstein AM, Macdonald 3rd AW, Ferrell RE, Halder I, et al. The brain-derived neurotrophic factor Val66Met polymorphism moderates an effect of physical activity on working memory performance. Psychol Sci. 2013;24:1770-9.

43. Brown BM, Bourgeat P, Peiffer JJ, Burnham S, Laws SM, Rainey-Smith SR, et al. Influence of BDNF Val66Met on the relationship between physical activity and brain volume. Neurology. 2014;83:1345-52.

44. Folstein MF, Folstein SE, McHugh PR. "Mini-mental state": A practical method for grading the cognitive state of patients for the clinician. J Psychiatr Res. 1975;12:189-98.

45. Wechsler D. WMS-R: Wechsler memory scale-revised. New-York: Psychological Corporation; 1987.

46. Wechsler D. Échelle clinique de mémoire de Wechsler - 3ème édition. Paris: ECPA; 2001.

47. Jackson AS, Blair SN, Mahar MT, Wier LT, Ross RM, Stuteville JE. Prediction of functional aerobic capacity without exercise testing. Med Sci Sports Exerc. 1990;22:863-70.

48. Nguyen JCD, Killcross AS, Jenkins TA. Obesity and cognitive decline: role of inflammation and vascular changes. Front Neurosci. 2014;8:375.

49. Kriska AM, Sandler RB, Cauley JA, Laporte RE, Hom DL, Pambianco G. The assessment of historical physical-activity and its relation to adult bone parameters. Am J Epidemiol. 1988;127:1053-63. 
50. Ainsworth BE, Haskell WL, Herrmann SD, Meckes N, Bassett Jr DR, TudorLocke C, et al. 2011 compendium of physical activities: a second update of codes and MET values. Med Sci Sports Exerc. 2011;43:1575-81.

51. Bourque P, Blanchard L, Vézina J. Étude psychométrique de l'Échelle de dépression gériatrique. Can J Aging. 1990;9:348-55.

52. Yesavage $J A$, Brink $T L$, Rose $T L$, Lum $O$, Huang V, Adey M, et al.

Development and validation of a geriatric depression screening scale: a preliminary report. J Psychiatr Res. 1983;17:37-49.

53. Mata J, Thompson RJ, Gotlib IH. BDNF Genotype Moderates the Relation Between Physical Activity and Depressive Symptoms. Health Psychol. 2010;29:130-3.

54. Bryan A, Hutchison KE, Seals DR, Allen DL. A Transdisciplinary Model Integrating Genetic, Physiological, and Psychological Correlates of Voluntary Exercise. Health Psychol. 2007;26:30-9.

55. Farfel JM, Nitrini R, Suemoto CK, Grinberg LT, Ferretti REL, Leite REP, et al. Very low levels of education and cognitive reserve: a clinicopathologic study. Neurology. 2013;81:650-7.

56. Stern Y. Cognitive Reserve: Implications for Assessment and Intervention. Folia Phoniatr Logop. 2013;65:49-54.

57. Booth FW, Chakravarthy MV, Spangenburg EE. Exercise and gene expression: physiological regulation of the human genome through physical activity. J Physiol. 2002;543:399-411.

58. Ratey JJ, Loehr JE. The positive impact of physical activity on cognition during adulthood: a review of underlying mechanisms, evidence and recommendations. Rev Neurosci. 2011;22:171-85.

59. Vaynman S, Gomez-Pinilla F. Revenge of the "Sit": How lifestyle impacts neuronal and cognitive health through molecular systems that interface energy metabolism with neuronal plasticity. J Neurosci Res. 2006;84:699-715.

60. Beste C, Baune BT, Domschke K, Falkenstein M, Konrad C. Paradoxical association of the brain-derived-neurotrophic-factor val66met genotype with response inhibition. Neuroscience. 2010;166:178-84.

61. Pezawas L, Verchinski BA, Mattay VS, Callicott JH, Kolachana BS, Straub RE, et al. The brain-derived neurotrophic factor val66met polymorphism and variation in human cortical morphology. J Neurosci. 2004;24:10099-102.

62. Hariri AR, Goldberg TE, Mattay VS, Kolachana BS, Callicott JH, Egan MF. Brain-derived neurotrophic factor val66met polymorphism affects human memory-related hippocampal activity and predicts memory performance. J Neurosci. 2003;23:6690-4.

63. Tsai S-J, Gau Y-TA, Liu M-E, Hsieh C-H, Liou Y-J, Hong C-J. Association study of brain-derived neurotrophic factor and apolipoprotein E polymorphisms and cognitive function in aged males without dementia. Neurosci Lett. 2008;433:158-62.

\section{Submit your next manuscript to BioMed Central and we will help you at every step:}

- We accept pre-submission inquiries

- Our selector tool helps you to find the most relevant journal

- We provide round the clock customer support

- Convenient online submission

- Thorough peer review

- Inclusion in PubMed and all major indexing services

- Maximum visibility for your research

Submit your manuscript at www.biomedcentral.com/submit
Biomed Central 